\title{
Team Project Patterns for College Students
}

\author{
Darren Hayes \\ Pace University \\ 163 William Street \\ New York, NY 10038 \\ (212) 346-1005 \\ dhayes@pace.edu
}

\author{
Jonathan Hill \\ Pace University \\ 163 William Street \\ New York, NY 10038 \\ (212) 346-1864 \\ jhill@pace.edu
}

\author{
Anne Mannette-Wright \\ Pace University \\ 163 William Street \\ New York, NY 10038 \\ am09812w@pace.edu
}

\author{
Henry Wong \\ Pace University \\ 163 William Street \\ New York, NY 10038 \\ (212) 346-1005 \\ hwong@pace.edu
}

\section{Keywords}

Patterns, Team Project, College Students.

\section{INTRODUCTION}

Team Project Patterns for College Students is a pattern language intended for use by faculty instructing college students. The language is not designed for the college or university environment where courses are taught online but rather can be applied universally to third level education. There are two goals with implementing these patterns: (i) Team Building and (ii) Enhance Shared Learning. In writing these patterns, we were using examples of semester-long projects.

Team project dynamics are can be very problematic. The motivations for students to perform well in a college setting are somewhat different from the workplace but if we can provide proven team patterns for the academic world then perhaps we can ultimately improve team project work outside of the classroom. Common issues, that we have sought to address, include improving team structure, promoting equality for individual contributions, thereby ultimately advancing the quality of student deliverables. Moreover, students will feel greater pride in their work and produce a superior product, which is a huge motivator for our work on team patterns.

Currently, students are generally apathetic towards team work, especially those who feel that they are conscientious about performance metrics and know that they will have to pick up the slack of those who do not care about their grade but simply hope to pass the class. Communication slowly deteriorates as the work continues, which also promotes deterioration in student motivation, pride, experience and product quality. It is true that student motivations are different in an academic setting but one can imagine that much of the pattern language contained in this paper is applicable in the workplace. After all, pride is a great motivator for producing a superior product. If students or employees do not enjoy their work, do not have a well structured plan to adhere to and do not experience a meaningful contribution by all team members, then project quality suffers.

Permission to make digital or hard copies of all or part of this work for personal or classroom use is granted without fee provided that copies are not made or distributed for profit or commercial advantage and that copies bear this notice and the full citation on the first page. To copy otherwise, to republish, to post on servers or to redistribute to lists, requires prior specific permission and/or a fee.

PLoP '06, October 21-23, 2006, Portland, OR, USA.

Copyright 2006 ACM 978-1-60558-151-4/06/10_..\$5.00.
This patterns language is related to the pattern GROUPS WORK [2]. The GROUPS WORK pattern provides a solution that emphasizes group work in courses that are small or large groups, in both the long-term (weeks) and in the short-term (minutes) duration. The intent of the language is to provide a common base of knowledge for teaching faculty of undergraduate college or university students in regard to the usage of team projects within courses. The size of the groups is not limited; the time range is approximately one semester in length. The patterns seek to provide a set of best practices for teaching faculty to follow in initiating, monitoring, mentoring and assessing student team projects.

Figure 1 below illustrates the connections between the patterns we have developed. The diagram starts with the one of two patterns that would be applied at the beginning of a project, PROFESSOR PROVIDES TOPICS and PROFESSOR FORMS TEAMS. These patterns are followed by the pattern DEFINE ROLES AND RESPONSIBILITIES which would occur in the early stages of a project. DEFINE ROLES AND RESPONSIBILITIES would be followed by STAGED PROJECT DELIVERABLES and EVERY INDIVIDUAL PRESENTS. At the midpoint of a project the pattern MID SEMESTER TEMPERATURE CHECK would be applied which would be followed by ASSIGNING PROJECT GRADES at the conclusion of the project.

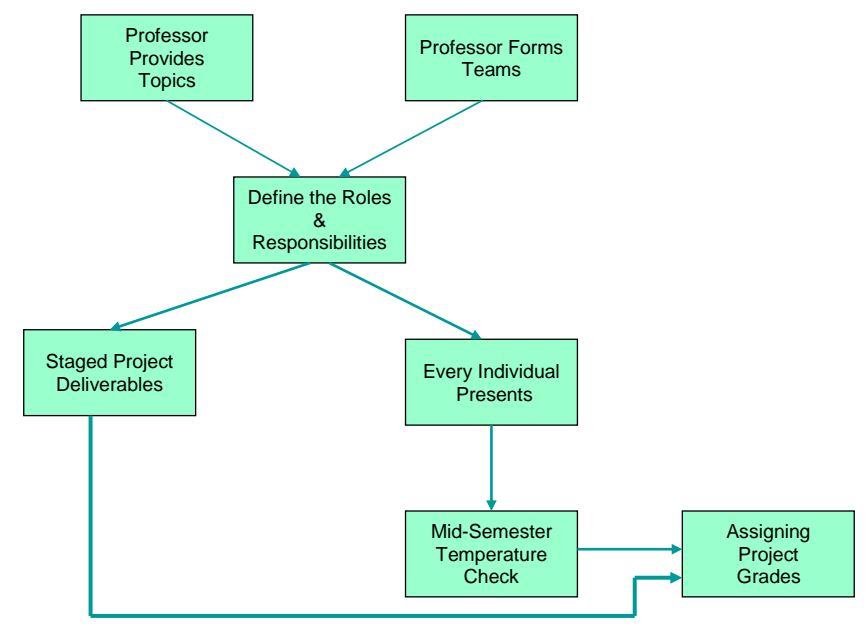

Figure 1

\section{FORMAT OF THE PATTERNS}


The following provides a schema for the format of the patterns. Format

Name

Context sentence: Who the pattern is addressed to and when it can be applied.

Problem paragraph. The key sentence in italics.

Forces paragraphs. What do you need to consider in order to apply this pattern (bulleted lists)

Solution. Key sentence is in italics.

Commentary and consequences paragraphs

Examples

Related Patterns (if applicable)

\subsection{Name: Assigning Project Grades Context:}

This pattern is applied to college students who are required to perform a variety of different team projects during the semester.

\section{Problem:}

Typically, the contribution made by individuals to the project varies greatly. A problem exists as to how to assign grades to students who participate on team projects. In academia, especially at undergraduate level, a lack of commitment, by certain students, is often more apparent.

\section{Forces:}

- In a way there is a contradiction with setting a team assignment and then saying that an individual grade will be awarded but the student will learn more from receiving an individual grade.

- There can be situations where a team member is shunned and is not allowed by others to make a contribution but this can be remedied if the professor clearly indicates that she is there to help resolve any issues.

- $\quad$ Perhaps the team will not inspire non-performing members, given the fact that their grade will not suffer as a result of another being inept but experience has shown that this is not the case.

- Working in teams, in an academic environment is challenging because the students are not used to working with other team members, in most cases, which is different from the corporate world of team projects.

Therefore, awarding an individual grade is more beneficial. The instructor must teach team skills if she is to expect that the team will work well together.
- Team spirit should be instilled in the students, by the instructor, to ensure that a team project succeeds and that the outcome of the whole project is as important as the experience.

\section{Solution:}

When introducing a team project to the class, the instructor will make it clear that even though it is a team project, ultimately each member of the team will receive an individual grade. The Professor should assign the majority of the grade, based on individual effort and some on team effort to encourage members to support each other. When this expectation is made at the beginning of the project, then contributions made by individual team members may be more evenly distributed. When students know that grading will be rendered according to individual effort, as well as team effort, then individual efforts increase and usually a better project is developed.

\section{Consequences:}

Students will approach their assignment in a more positive manner and will provide a better individual commitment, in teams where there could be problems associated with all team members making a contribution.

\section{Examples:}

This pattern seems to work in the classroom, whenever it was instituted. On one occasion, we noted that students were very disheartened about the prospect of working in a team project, given past experiences of the unequal efforts of team members. When we announced that roles would be clearly defined, in the project guidelines and that deliverables must met, by each individual, by a certain date, or a grade would not be forthcoming for that person(s) and that the team would not suffer, then students were very satisfied. There were no problems with team dynamics reported to the instructor.

It is important to note that for the most part, team members will work well together throughout the semester. However, typically each semester there is at least one team which will encounter problems with individual contributions; in general we are talking in terms of 20-30 students with approximately 4-7 teams.

\section{Related Patterns:}

FAIR PROJECT GRADING [1]

FAIR TEAM GRADING [5]

\subsection{Name: Mid-Semester Temperature Check Context:}

Students are asked to work on a team project, during the semester, and will then be graded on their in-class presentation and corresponding paper. Students need the opportunity to learn from their early mistakes. 


\section{Problem:}

If a teacher waits until the end of the semester to look at a team project then the teacher may have little or no input in guiding students to produce a superior deliverable. Team projects are very often left by the wayside, by students, until the end of the semester.

\section{Forces:}

- Students may feel that a mid-semester presentation is not that important if the final grade is based upon the final presentation and paper submission.

- Constructive criticism may be taken personally to the more sensitive students

- Students could potentially laugh at some presenters or presentations, which can be taken to heart by some. However, we have never experienced this.

- $\quad$ Some students may have speech impediments or be very nervous. When students realize that everyone goes through the process, they are generally not too concerned.

\section{Solution:}

Have the students make a mid-semester presentation so that they can be better prepared for the final presentation. The students are asked to present their term paper, in front of their peers and the teacher. The teacher will then make suggestions about what they like and what needs to be changed, prior to the final presentation. We would recommend that no grade is assigned to the presentations, mid-semester, so that students really feel that they are being given another chance to really improve their work.

\section{Consequences:}

When students have the chance to make a mid-semester presentation the teacher can see if the team is on the right course and can offer them the chance to make changes. Providing this mid-semester opportunity for BUILT-IN FAILURE "removes the fear of failure as a barrier to learning by making failure a part of the learning process". [3] Students will have the opportunity to have a second chance at making things right, can have more coaching on improving their presentation skills and sense that the teacher is being fair by allowing them to have a second chance.

\section{Examples:}

We have noticed that when students make a mid-semester presentation, they are actually grateful for the guidance and feel that they can better prepare for their final appearance. The midsemester presentation is the work that the teams have completed so far for the semester project. When a mid-semester presentation does not exist then students can feel embarrassed, sense a lack of support or indignant when their project was poorly presented. The instructor can also get a feel early on what the individual contributions have been and intervene more effectively when team dynamics are simply not working out and the blame game begins.

\section{Related Patterns: \\ BUILT-IN FAILURE [3]}

\subsection{Name: Define the Roles \& Responsibilities in Advance \\ Context:}

When students first set up in teams it can be both difficult and time-consuming for them to understand what their role and responsibilities will be in a team. It is important to define the roles and responsibilities in advance so that each student understands exactly what is expected of them.

\section{Problem:}

History shows that there is a very disproportionate contribution made by individual students within a team. Students who carry the work load for others will often feel let down and indignant. The problem can stem from the fact that there needs to be clear definitions of individual roles and responsibilities.

\section{Forces:}

- Students in a college environment need to have more flexibility than they did in high school so that they can learn problem solving in a team project. Setting too many rules detracts from that.

- Students can feel discontented with their role and may feel that they would have benefited more from exposure to more than one position in the team. This can be especially true when a student joins the class late or was absent when teams were first created.

- The number of students enrolled in a class very rarely breaks evenly into teams with the appropriate roles so that one or more teams may not benefit as much as other teams when roles are predefined.

- Students may decide to work independently and not help members who may struggle and not be team players if they feel that they are only required to fulfill a certain obligation to gain a good grade.

- There could be a void in a project if a team member does not complete the work or perhaps drops the class.

\section{Solution:}

Decide on roles, responsibilities and timelines for deliverables in advance to ensure that students have a greater understanding of their deliverables and so that it is clear who is potentially 
responsible for poor performance and who completed their tasks or exceeded expectations. Student expertise will vary greatly, especially where each student will take different classes at different times, during their degree program. Polling the class at the beginning of the semester can help in deciding on roles and responsibilities. The teacher might decide to let the students pick their own position or might assign it but what is important is that the instructor clearly outlines what is expected from each student.

\section{Consequences:}

Students who are provided a good structure, or framework, to work within, will know what is expected and when it is expected. Moreover, they can feel secure in the knowledge that there is a system designed to protect them and judge them effectively on both team work and individual contribution.

\section{Examples:}

Predefining roles works in practice because it is a good project management practice and is need more in the corporate world. Too often projects fail because there is a lack of accountability. Students have felt more comfortable about being graded fairly when roles are clearly defined when teams are first created.

\subsection{Name: Professor Forms Teams} Context:

This pattern is applied in the situation where a team project has been assigned and students are currently not organized into teams.

\section{Problem:}

A team project has been assigned and teams do not yet exist in the class. Should the instructor form the teams i.e. assign the students to teams or should the students be allowed to form their own teams?

\section{Forces:}

- Some students may feel "left out" as students form teams based on their friendships with other students in the class.

- Students may form teams solely based on existing friendships with other students in the class. Thus could lead to "group think" within the team as students from similar backgrounds tend to have the same opinions or viewpoints.

- Students forming their own teams may result in teams containing students of the same skill level with little or no opportunity for weaker students to learn from other academically stronger students in the classroom.

- If the class consists of students who do not live in physical close proximity to one another i.e. some students live "on campus" and some live "off campus" it may be difficult for the students to meet as often as the team needs to meet.

- Students may dislike being assigned to teams.

- Self-forming teams can often be very successful.

- The professor needs to know all of the students well for this to work effectively.

\section{Solution:}

The Professor should assign students to teams based on the knowledge she has of the skill level of the students, their academic backgrounds and other pertinent information. The Professor will have to do some extra research to ensure that she has not paired students together who do not live in physically close proximity and thus would find it difficult to meet regularly. The intent here is to (i) spread skills across teams and (ii) split up any cliques, which may exist.

\section{Consequences:}

The teams will consist of students that will enable of the students on the team to learn and achieve their best performance. A possible consequence is that there may be interpersonal conflicts between team members who are of incompatible personality types. As a result, the team may prove to be ineffective and need to be dissolved and new teams formed. The intent of this pattern is to spread skills proportionately across teams as well as to break up student cliques.

\section{Examples:}

One of the authors has used both approaches (students form teams and professor forms teams) in the classroom and has found the "professor forms team" approach to be more effective. Students forming teams usually led to students combining with students of similar mindset, abilities, and quite often students who were acquainted or friends with other students in the class. A better experience in team-building was gained by the students.

When teaching a Web Design class, which has a service learning component, to undergraduate students, who are not technology majors, it was extremely helpful to determine which students had technology expertise so that the knowledge base could be spread across the teams.

This pattern differs from SELF-SELECTING TEAM [5] which can be used in an organizational industry setting where teams are self-selecting. This pattern is closely related to the pattern TEACHER SELECTS TEAMS [2]. TEACHER SELECTS TEAMS [2] is applied when a short team project that lasts between one class session and three weeks is assigned.

\section{Related Patterns:}

TEACHER SELECTS TEAMS [2]

SELF-SELECTING TEAMS [4]

\subsection{Name: Professor Provides Topics Context:}


This pattern is applied in the situation where a team project has been assigned and specific topics have not been assigned. Students are free to decide on the topic for their project.

\section{Problem:}

A team project has been assigned and specific topics for the project have not been given by the Professor. Some of the student teams are having difficulty on deciding on a specific topic for their project. Should the Professor provide some "suggested" topics or let the students determine their own topic? Students who are having difficulty deciding on a topic will have less remaining time to actually work on their project compared to those teams for which deciding on the topic was a relatively easy task.

\section{Forces:}

- Some student teams may have great difficulty in deciding on a topic for their project.

- Students who have difficulty in deciding on a topic will have less remaining time to actually work on their project.

- The Professor will have to do some extra "work" in providing topics to students.

\section{Solution:}

The Professor should provide the students with a "suggested" list of topics. This list should not be extensive enough to provide topics to all teams in the class otherwise the students may take the "easy road" and just pick a suggested topic giving little or no thought to what a good project topic is.

\section{Consequences:}

For student teams that are having difficulty in deciding on a topic the application of this pattern will eliminate the problem. The team will immediately be able to focus on a topic and start to work on their project. The Professor runs the risk of reducing the creativity of the students by supplying topics. In addition, the students may not use their creativity as much as possible on the remainder of the project given the fact that their project began with someone, i.e. the Professor providing the topic.

\section{Examples:}

One of the authors tried the approach of not supplying any topics for team based projects in a class. Some teams were successful in creating their own topics. This pattern worked well in those cases in which the teams were composed of students for which the material was proving difficult; for students where this was their initial exposure to the subject matter and they were having great difficulty; and for those students who were uninterested in the course material but were taking the course to meet degree requirements. It is speculated that this approach worked because it satisfied the needs of all of the aforementioned groups of students and got them started on their projects. The Professor saw no difference in the quality of the projects produced by those teams who were given topics as compared to those teams who were not given topics.

\subsection{Name: Staged Project Deliverables Context:}

This pattern is applied when a team project has been assigned and there are several identified deliverables for the project. This pattern applies primarily in the context of projects given to freshman or sophomores.

\section{Problem:}

A team project has been assigned and the Professor has not specified any specific time frame for any of the deliverables indicated in the project. Some of the teams may be mature enough to be able to effectively schedule when the deliverables should be done and be able to keep to such a schedule; other teams may leave everything to the proverbial "last minute". Should the Professor mandate when specific deliverables are due and make the teams submit these deliverables by their due dates?

\section{Forces:}

- Some student teams especially in freshman and sophomore year classes may not be mature enough to recognize that they should complete deliverables by certain dates. As a result, some teams may leave many deliverables until the very end of the project resulting in an accelerated pace for the work and perhaps lower quality work.

- The Professor can set the dates for project deliverables and require the students to pass in the deliverables by specific due dates. This in effect forces the students to work on the project in a staged, controlled manner and ensures that they will complete all of the required work.

\section{Solution:}

The Professor should provide the students with a list of the "major" deliverables and their due dates for the project. This list should not include ALL deliverables required through the duration of the project but rather just the "major" ones. This is important as it should be a part of the schedule. It can be included in the course syllabus or be a part of a separate team project guidelines document.

\section{Consequences:}

For student teams that have a lower level of maturity this pattern will set a schedule for the major deliverables of the project. The students should then be able to determine the work that needs to be done between these delivery dates as a "partial" schedule has already been set for them. Having the students submit major deliverables at specific points in time throughout the duration of the project enables the Professor to provide feedback to the students in regard to the quality of their deliverables prior to the final project completion date. An additional benefit to the 
students is that this then enables them to make revision to deliverables prior to the project completion date.

This pattern differs from the MID-SEMESTER TEMPERATURE CHECK pattern in that it specifies deliverables and deliverable dates for the project. These "deliverables" may or may not include a mid-semester presentation.

\section{Examples:}

Predefining due dates for major deliverables in effect sets an outline of a schedule for a project. For projects assigned in lower level undergraduate years, i.e. freshmen and sophomore, this can "force" the students into a schedule. One of the authors of this paper has tried assigning team projects with and without mandated dates for major deliverables and always observed that students produce better quality projects when a schedule was mandated using this pattern.

\subsection{Name: Every Individual presents Context:}

This pattern is applied when the project is complete and the team must present their project before their peers in class.

\section{Problem:}

Sometimes students feel that the burden of the project is unevenly distributed and this will carry forward to the day of the presentation. The instructor must decide whether every student must present or those that feel confident enough to present.

Forces:

- Some students may feel inadequate and unable to present.

- $\quad$ Some students can feel embarrassed or nervous presenting in front of a class.

- If every student presents then there may not be enough time in one class for everyone to speak.

- Late arrivals to class may delay some of the presentations.

- An absence by a team member may cause a presentation to lack important elements.

\section{Solution:}

Every student must present so that every student will (a) benefit from learning to present and (b) stand beside their team members and share the responsibilities. Parameters need to be predetermined. For example, each student will speak for five minutes and have a maximum of three slides (perhaps PowerPoint), for their contribution. For those who have difficulty in presenting, the instructor can allow the student to read from notes and those with special needs can be allotted extra time to finish. Using a slide presentation can help students to express themselves.

\section{Consequences:}

This scenario first appears to be fraught with peril but it has always proved to be successful. Students feel safe when they are allowed to use notes and are told that their oratory is not being graded but that the experience is merely to aid them in their careers. This ensures that nobody will run off the stage or break down.

\section{Examples:}

One of the benefits that has been seen in practice is that the only students who are ever embarrassed are those who have not done the work and it is clear that their presentations are defunct of meaningful information or when students ask questions they seem ignorant.

\section{ACKNOWLEDGMENTS}

We owe a great deal of gratitude to our Shepherd, Till Schümmer. Without Till, our paper would not be close to the standard that it has reached. The success of our collaboration, with our shepherd, actually strengthens the validity of our patterns, which seek to shepherd student teams, through a structured process, which greatly enhances the motivation of others to produce something of a superior quality. The work of Till has demonstrated the need and value of an alternative perspective as well as the universality of patterns.

\section{REFERENCES}

[1] Bergin, Joseph, "A Pattern Language for Course Development in Computer Science", obtained from http://csis.pace.edu/ bergin/patterns/coursepatternlanguage.h $\underline{\mathrm{tml}}$

[2] Bergin, Joseph, Eckstein, Jutta, Manns, Mary Lynn, Sharp, Helen, "Patterns for Active Learning", Proceedings of PLoP 2002.

[3] Bergin, Joseph, Marquardt, Klaus, Manns, Mary Lynn, Eckstein, Jutta, Sharp, Helen, Wallingford, Eugene, "Experimental Learning Patterns", Proceedings of EuroPLoP 2001.

[4] Coplien, James, Harrison, Neil, "Organizational Patterns of Agile Software Development”, Prentice Hall, 2005.

[5] Eckstein, Jutta, Bergin, Joseph, Sharp, Helen, "Feedback Patterns", Proceedings of EuroPLoP 2002. 